\title{
Effect of single nucleotide polymorphisms in the UCP3 and FOXO1 genes on carcass quality traits in Qinchuan cattle
}

\author{
L.S. Gui ${ }^{1,2}$ and J.L. Jia ${ }^{2,3}$ \\ Qinghai University \\ ${ }^{1}$ State Key Laboratory of Plateau Ecology and Agriculture, ${ }^{2}$ College of Agriculture and Animal Husbandry \\ Xining, 810016 Qinghai Province, People's Republic of China
}

KEY WORDS: UCP3, FOX01, single nucleotide polymorphism, carcass quality, cattle

Received: 28 December 2017

Revised: $\quad 2$ June 2018

Accepted: 15 November 2018

${ }^{3}$ Corresponding author: e-mail: qhdxdkfz@163.com

\begin{abstract}
Allelic and genotypic distributions of polymorphisms in the uncoupling protein 3 (UCP3) and forkhead box 01 (FOXO1) genes were assessed in 491 Chinese Qinchuan cattle. Single-locus genotype effects and the combined effect of polymorphisms within those two genes were probed to determine possible association with the carcass quality traits. Using DNA sequencing, in total three novel single nucleotide polymorphisms (SNPs) were identified, including a SNP in the intron 1 of UCP3 (NC_037339.1: g.6821C>T), and two SNPs within the 3'UTR of FOXO1 (NC_037342.1: g.93063G>A and g.93280A>G). Statistical analyses indicated that the g.6821C>T (UCP3) and g.93280A > G (FOX01) polymorphisms were significantly associated with intramuscular fat content $(P<0.05$ or $P<0.01)$. So, the results obtained in this study constitute a valuable information about the markers applicable in marker-assisted selection (MAS) used in improving carcass quality traits.
\end{abstract}

\section{Introduction}

As a subgroup of mitochondrial anion carriers (Erden et al., 2015), the family of uncoupling protein (UCP) consists of 7 members, including UCP1, UCP2, UCP3, UCP4, BMCP1, StUCP and AtUCP (Chen et al., 2016). Among these UCP homologues, UCP3 is localized in the inner mitochondrial membrane, and is believed to be involved in the control of lipid handling and the regulation of energy balance (Oliveira et al., 2016). In the previous studies it was indicated that UCP3 plays an important role in the fatty acid metabolism due to the decrease in mitochondrial production of reactive oxygen species (Toime and Brand, 2010) and increased capacity to store energy as fat (Saltzman and Roberts, 1995). Activation of UCP3 is indirectly regulated by norepinephrine and is dependent upon the availability of free fatty acids (Sprague et al., 2007). In UCP $3^{-/-}$mice after a long-term con- sumption of a high-fat diet, a significant increase in levels of adiposity was shown in comparison with UCP3tg mice, indicating that UCP3 is involved in the protection from fat gain induced by long-term high-fat feeding (Changani et al., 2003; Costford et al., 2008).

Localized in the nucleus, FOXO1, also known as FKHR, belongs to the FOXO1 subfamily of the forkhead transcription factor family. This classification reflects its role in glucose and lipid metabolism (Sparks and Dong, 2009). Recent studies on animal models and in vitro systems of human cells have determined that FOXO1 likely influences the differentiation of adipocyte precursors (Yan et al., 2013; Zou et al., 2014). The FOXO1 knock-out mice exhibit improved glucose tolerance and insulin sensitivity, accompanied with smaller-sized adipocytes. This likely occurred via influence of adipocyte size and adipose tissue-specific gene expression (PGC-1 $\alpha$, $\mathrm{UCP} 1, \mathrm{UCP} 2$ and $\beta 3-\mathrm{AR}$ ) in response to excessive 
calorie intake. Taken together, these reports demonstrate a possible mechanism through which FOXO1 modulates energy homeostasis in both white and brown adipose tissues (Nakae et al., 2008). Similarly, mice with a FOXO1 deletion exhibited increased expression of Pdk4 mRNA in white adipose tissue in comparison with wild-type littermates, thereby enhancing expression of peroxisome proliferator-activated receptor gamma (PPAR $\gamma)(\mathrm{Kim}$ et al., 2009). In 3T3-L1 adipocytes, knockdown of FOXO1 resulted in decreased expression of adipose triglyceride lipase (ATGL), and attenuated isoproterenol-stimulated lipolysis (Chakrabarti and Kandror, 2009). Therefore, FOXO1 represents a critical mediator of the lysosomal-mediated lipid catabolism in adipocytes during nutrient restriction and metformin treatment (Lettieri Barbato et al., 2013).

Based on the above data, it was hypothesized that UCP3 and FOXO1 may play an important role during bovine adipocyte development in Qinchuan cattle. Such a breed was chosen since it is widely considered to be a top indigenous breed in China. However, carcass traits, especially the intramuscular fat content, are significantly lower in this breed than in imported cattle selected for high levels of intramuscular fat, such as Wagyu cattle. Therefore, the objectives of this study were to estimate allele and genotype frequencies of the $U C P 3$ and $F O X O 1$ genes polymorphisms, as well as to evaluate associations between those polymorphisms and carcass quality traits in Qinchuan cattle.

\section{Material and methods}

Animal handling procedures were performed in accordance with the Guide for the Care and Use of Laboratory Animals. The animal study protocol was approved by the Institutional Animal Care and Use Committee of Qinghai University (China).

\section{Sample and data collection}

In total 491 female cattle (aging from 18 to 24 months) from 6 different sires were used in the experiment. They were randomly selected from the experimental farm of the National Beef Cattle Improvement Center in Yangling (China). Calves were weaned at an average age of 6 months, and were transitioned to a diet of maize and maize silage, according to nutrient requirements of growing heifers (NRC, 2000). Heifers were offered feed and fresh water. All heifers were fed the same ratio of roughage to concentrate $(6: 4)$ and raised under similar conditions (temperature, humidity).

Genomic DNA was extracted from whole blood samples using a Blood RNA Kit (OMGAM BioTek, Doraville, GA, USA). Carcass quality traits, including backfat thickness, loin muscle area and intramuscular fat content of the longissimus dorsi muscle at the $12^{\text {th }}$ rib were determined using ultrasound based measurements (Aquila Pro Vet, PIE MEDICAL, Maastricht, Netherlands).

\section{Single nucleotide polymorphism (SNP) detection and genotyping}

Primers used to genotype individuals were designed using the Primer Premier 5.0 Software (Premier, Pala Alto, CA, USA), corresponding to the exons that represent the open reading frame of the FOXO1 (accession no. NC_037342.1) and UCP3 (accession no. NC_037339.1) genes published in GenBank. The primer sequences, annealing temperatures, PCR product lengths and primer locations are shown in Table 1.

The total volume of the PCR reaction was $20 \mu \mathrm{l}$, which contained $100 \mathrm{ng}$ of genomic DNA, $10 \mathrm{pM}$ of each upstream and downstream primer, $0.20 \mathrm{mM}$ dNTPs, $2.5 \mathrm{mM} \mathrm{MgCl}$ and $0.5 \mathrm{U}$ Taq polymerase (TaKaRa, Dalian, China). All PCR products were

Table 1. Primers used in the experiments

\begin{tabular}{|c|c|c|c|c|}
\hline Name & Primer sequence (5' to $\left.3^{\prime}\right)$ & $\mathrm{Tm},{ }^{\circ} \mathrm{C}$ & Product length, bp & Amplified region \\
\hline UCP3-L1 & $\begin{array}{l}\text { CAAACCTTCTCCTGGTGCTG } \\
\text { GGTGAGGTAGGGTCGTGAAT }\end{array}$ & 56.7 & 433 & Part of 5'UTR and part of exon 1 \\
\hline UCP3-L2 & $\begin{array}{l}\text { AAGCCATCACCCTCCGATTTAC } \\
\text { TCAGTCTCCTCATGCTTCAGCTT }\end{array}$ & 60.5 & 521 & Part of exon 1 \\
\hline UCP3-L3 & $\begin{array}{l}\text { CTCTAATGAGGTGGTTGGG } \\
\text { CCATCTTCAGCATACAGTCG }\end{array}$ & 61.7 & 601 & Part of exon 4 \\
\hline FOX01-L1 & $\begin{array}{l}\text { GAGCCGTGAAGTTAAGTTCTG } \\
\text { TAGGGCACGCTCTTGACCATC }\end{array}$ & 61.0 & 851 & Part of $5^{\prime} U T R$, exon 1 and part of exon 2 \\
\hline FOX01-L2 & $\begin{array}{l}\text { ATCGCAAATCTAAGTGGTT } \\
\text { CTCAGGGTTACTGATCTCG }\end{array}$ & 60.0 & 799 & Part of exon 3 \\
\hline FOX01-L3 & $\begin{array}{l}\text { CCAGACATTTGAAGCAGCAT } \\
\text { AAGAGCACAGCGTTACGAGG }\end{array}$ & 63.5 & 502 & Part of 3'UTR \\
\hline FOX01-L4 & $\begin{array}{l}\text { GTGAGGTTGAACGGGGGAAT } \\
\text { GATGGTTAGAGGGGTGGCTG }\end{array}$ & 59.5 & 601 & Part of 3'UTR \\
\hline
\end{tabular}


resolved using gel electrophoresis to verify amplification of the intended target. Amplicons were then sequenced using an ABI 3730 sequencer (ABI, Foster City, CA, USA).

\section{Data analysis}

Allele and genotype frequencies of bovine FOXO1 and UCP3 genes were directly estimated. Hardye-Weinberg equilibrium (HWE) was used to analyse the distribution of genotypes and to compare differences in the genotype distribution. Population genetic indices, including gene heterozygosity (He, the proportion of heterozygote at gene specific loci) and polymorphism information content (PIC) were calculated using a web-based tool (http://www.msrcall.com/Gdicall.aspx). The linkage disequilibrium (LD) structure as measured by $r^{2}$ (correlation coefficient) was performed with Haploview software.

Associations between several carcass quality traits and SNPs in Qinchuan cattle were tested using the general linear models (GLM) in SPSS 18.0 software (IBM, Armonk, NY, USA). The basic linear model was:

$$
\mathrm{Y}_{\mathrm{ijk}}=\mathrm{u}+\mathrm{G}_{\mathrm{i}}+\mathrm{A}_{\mathrm{j}}+\mathrm{S}_{\mathrm{k}}+\mathrm{E}_{\mathrm{ijk}},
$$

where: $G_{i}$ - fixed effect of genotype ( $i=1,2$ and 3$)$, $A_{j}$ - fixed effect of age $(j=1,2,3$ and 4$), S_{k}-$ random effect of sire $(\mathrm{k}=1$ through 6$)$ and $\mathrm{E}_{\mathrm{ijk}}$-random error.

\section{Results and discussion}

\section{Polymorphisms and genetic diversity}

As it is presented in Figure 1, three variations were identified through DNA sequencing analysis, including one novel SNP mapping in intron 1 of UCP3 (g.6821C > T), and two novel SNPs within the 3'UTR of FOXO1 (g.93063G $>$ A and g.93280A > G).

Allelic and genotypic frequencies, $\mathrm{He}, \mathrm{PIC}$ and HWE are presented in Table 2. The highest frequencies of alleles were $\mathrm{C}$ for g. $6821 \mathrm{C}>\mathrm{T}, \mathrm{G}$ for
g.93063G $>$ A and A for g.93280A $>\mathrm{G}$ in Qinchuan cattle populations. The $\chi^{2}$ test showed that those three SNPs were in agreement with the HWE $(P>0.05)$.

The PIC was calculated for each locus and the PIC values for SNPs and ranged from 0.287 to 0.309 , as detailed in Table 2. Moreover, according to the convention for the classification of PIC (Botstein et al., 1980), the experimental populations exhibited intermediate levels of polymorphism $(0.25<$ PIC $<0.50)$.

\section{LD analysis}

To determine possible linkage relationships between the g.93063G $>$ A and g.93280A $>$ G SNPs observed in Qinchuan cattle, the LD was estimated. Value for D' was 0.012 , and $r^{2}$ value was 0.001 . Taken together, these data indicate weak linkage between these two SNPs.

\section{Association analysis}

Data on the associations between single biomarkers and carcass quality traits in the studied population of Qinchuan cattle are presented in Table 3.

It has been demonstrated previously that a polymorphism (g.3076A $>\mathrm{G}$ ) within the UCP3 gene in a Korean cattle breed was significantly correlated with the meat yield and marbling scores (Chung et al., 2011). Also, two SNPs (g.4877C $>\mathrm{G}$ and g.4902C $>$ T) were identified in Qinchuan cattle and thought to be associated with growth and meat quality traits (Wang et al., 2016). Additionally, polymorphisms in UCP-3/BglI were associated with body length, and body length and heart girth in 6 month old and 24 month old Nanyang cattle, respectively (Zhang and $\mathrm{Li}, 2011$ ). In the present study, one SNP (g.6821C $>\mathrm{T}$ ) was detected in intron 1. Statistical analysis showed that animals possessing the $\mathrm{CC}$ genotype had significantly higher intramuscular fat content than those with the TT genotype $(P<0.05)$, demonstrating that $\mathrm{C}$ allele

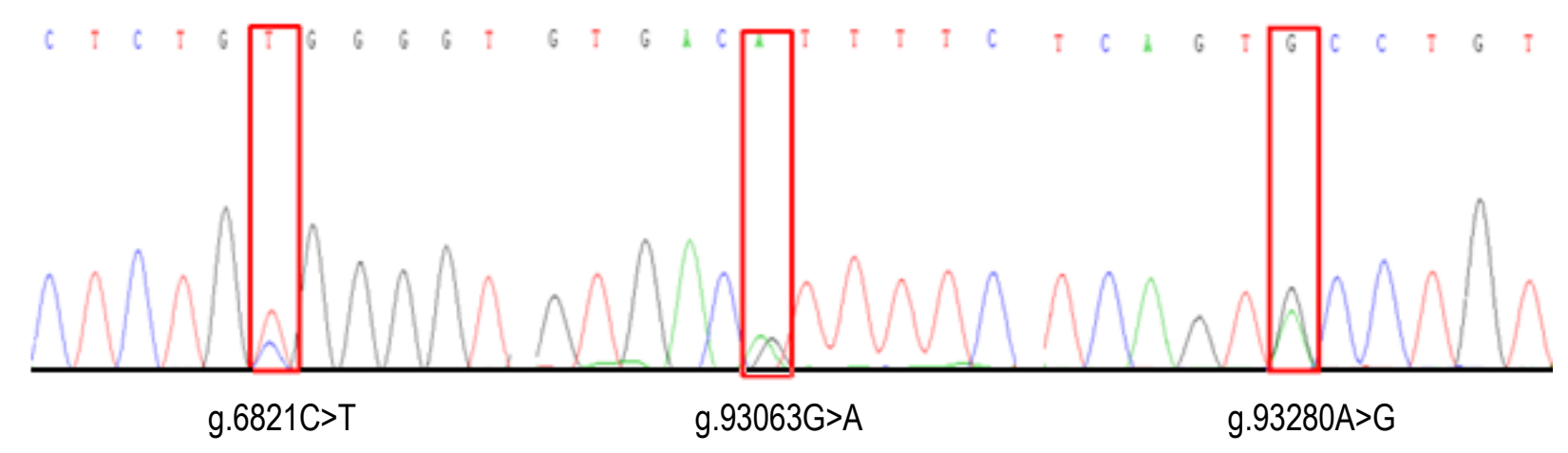

Figure 1. The sequencing map of the examined single nucleotide polymorphisms (SNPs) 
Table 2. Genotype frequencies (\%) of the UCP3 and FOXO1 genes for the single nucleotide polymorphisms (SNPs)

\begin{tabular}{llllllll}
\hline Locus & Genotype & & & PIC & $\begin{array}{l}\text { Maximum allele } \\
\text { frequency }\end{array}$ & He & $\begin{array}{l}\text { HWE } \\
(P \text {-value })\end{array}$ \\
\hline g.6821C>T & CC & CT & TT & 0.309 & $0.743(\mathrm{C})$ & 0.382 & 0.057 \\
& $(0.568)$ & $(0.350)$ & $(0.082)$ & & & & $(P=0.812)$ \\
g.93063G>A & GG & GA & AA & 0.302 & $0.754(\mathrm{G})$ & 0.371 & 0.017 \\
& $(0.652)$ & $(0.204)$ & $(0.144)$ & & & & $(P=0.897)$ \\
g.93280A>G & AA & TA & GG & 0.287 & $0.776(\mathrm{~A})$ & 0.348 & 0.915 \\
& $(0.613)$ & $(0.326)$ & $(0.061)$ & & & & $(P=0.339)$ \\
\hline
\end{tabular}

$\mathrm{PIC}$ - polymorphism information content, He - heterozygosity, HWE - Hardy-Weinberg equilibrium, $\mathrm{X}_{0.05(1)}^{2}=3.840, \mathrm{X}_{0.01(1)}^{2}=6.630$

Table 3. Association of different genotypes of single nucleotide polymorphisms (SNPs) in UCP3 and FOXO1 with carcass quality traits in Qinchuan cattle

\begin{tabular}{lllll}
\hline Locus & Genotypes $(\mathrm{N})$ & $\begin{array}{l}\text { Backfat thickness, } \\
\mathrm{cm}\end{array}$ & $\begin{array}{l}\text { Ultrasound loin muscle area, } \\
\mathrm{cm}^{2}\end{array}$ & $\begin{array}{l}\text { Intramuscular fat content, } \\
\%\end{array}$ \\
\hline g.6821C>T & CC (279) & $1.004 \pm 0.018$ & $64.856 \pm 0.455$ & $7.455 \pm 0.032^{\mathrm{a}}$ \\
& CT (172) & $0.955 \pm 0.023$ & $63.392 \pm 0.579$ & $7.035 \pm 0.040$ \\
& TT (40) & $0.950 \pm 0.049$ & $63.175 \pm 1.201$ & $6.391 \pm 0.084^{\mathrm{b}}$ \\
& P-value & 0.096 & 0.051 & 0.038 \\
g.93063G>A & GG (320) & $0.980 \pm 0.017$ & $64.308 \pm 0.424$ & $7.171 \pm 0.034$ \\
& GA (100) & $0.984 \pm 0.031$ & $63.106 \pm 0.759$ & $7.271 \pm 0.061$ \\
& AA (71) & $0.995 \pm 0.037$ & $65.627 \pm 0.901$ & $7.340 \pm 0.073$ \\
& P-value & 0.714 & 0.188 & 0.149 \\
g.93280A>G & AA (301) & $1.022 \pm 0.018^{\mathrm{A}}$ & $64.969 \pm 0.437$ & $7.481 \pm 0.028^{\mathrm{A}}$ \\
& AG (160) & $0.932 \pm 0.024^{\mathrm{a}}$ & $63.046 \pm 0.599$ & $6.925 \pm 0.038$ \\
& GG (30) & $0.859 \pm 0.056^{\mathrm{Bb}}$ & $63.517 \pm 1.383$ & $6.100 \pm 0.088^{\mathrm{B}}$ \\
& P-value & 0.002 & 0.071 & 0.000 \\
\hline
\end{tabular}

${ }^{\mathrm{ab}}$ and ${ }^{\mathrm{AB}}$ - means with different superscripts are significantly different at $P<0.05$ and $P<0.01$, respectively

might be associated with an increase in intramuscular fat content in Qinchuan cattle. Growing evidence suggests that mutations within introns may regulate the transcriptional efficiency of genes through either splicing or disruption of critical DNA protein interactions in a variety of organisms (Hull et al., 2007). In the current paper, bioinformatics analysis using the SplicePort software predicted the effects of the SNP g.6821C > T in the intron of the UCP3 gene on the alternative splicing (Dogan et al., 2007). The data indicated that the SNP g.6821C $>$ T is located in the initial parts of Donor (Sequence: gCggggtgtccc, Score value: -1.65335$)$. Thus, it can be reasonably inferred that the mutation at $\mathrm{g} .6821 \mathrm{C}>\mathrm{T}$ may alter UCP3 gene transcription by modifying alternatively spliced transcripts. The g.6765T $>$ C SNP in intron 2 of the $V E G F$ gene was observed to exert a significant contribution to the body weight and heart girth of Chinese cattle breeds, which was assessed using PCR-SSCP and DNA sequencing (Pang et al., 2011). The g.1948A $>$ G SNP of intron 2 in the MYF5 gene resulted in significant changes in the backfat thickness as well as live weight at 6 month old Hanwoo cattle
(Seong et al., 2011). Nevertheless, additional studies are required to clarify the associations between this intronic mutation and carcass quality traits in Qinchuan cattle.

It was previously reported by Sun et al. (2013) that the identified three polymorphisms within the FOXO1 gene (C1245A, G1732A and A176183G) were associated with growth traits in Qinchuan cattle. However, detailed information with respect to the possible association between bovine $\mathrm{FOXO1}$ genotypes with carcass quality traits in Chinese beef cattle are lacking. In the present study, two SNPs were detected in the 3'UTR (g.93063G $>$ A and g. $93280 \mathrm{~A}>\mathrm{G}$ ). At the g.93280A $>\mathrm{G}$ locus, statistical analysis indicated that the individuals carrying the AA genotype had significantly greater backfat thickness and intramuscular fat content than those with GG genotype $(P<0.01)$. This implicates that A allele might be possibly associated with an increase in backfat and intramuscular fat contents in Qinchuan cattle. Genotypes of locus g.93063G $>$ A were not significantly correlated with carcass quality traits $(P>0.05)$. The 3'UTR miRNA-related SNPs may 
be within or at the vicinity of the miRNA binding site, which could impair regulatory functions of the associated miRNA. This could result in variations in the level or timing of gene expression, ultimately affecting phenotypes (Trott et al., 2014), as has been previously demonstrated in pigs (Bartz et al., 2014) and goats (Hou et al., 2015; An et al., 2016). In the current paper, bioinformatics analyses were used to predict the effects of the SNP g.93280A $>\mathrm{G}$ in the 3'UTR of the FOXO1 gene on the miRNA binding sites using Targetscan (http://www.targetscan. org/vert). The data indicated that Allele g.93280A presents a binding site exclusively for miR-2298, while g.93280G did not exhibit affinity to any known miRNAs. Thus, it can be reasonably inferred that the mutation at g.93280A $>\mathrm{G}$ may alter FOXO1 gene expression level by modifying miRNA binding sites within the 3'UTR. As a result, the mutation could affect fatty acid metabolism in Qinchuan cattle.

Meat quality traits including tenderness, colour, flavour and juiciness, are economically important traits that receive considerable attention in cattle breeding. Furthermore, these traits are heavily dependent upon the level of fat deposition (Hausman et al., 2014). Among four types of bovine adipose tissue, intramuscular fat is the most important in terms of flavour, juiciness, water holding capacity and tenderness (Cui et al., 2012; Ramayo-Caldas et al., 2014). Programmes employing marker-assisted selection (MAS) through the analysis of gene polymorphisms involved in the main metabolic pathways related to animal growth and distribution of nutrients among different tissues could select particularly beneficial traits that have low heritability (Zhang and Li, 2011).

\section{Conclusions}

Three single nucleotide polymorphisms (SNPs) were observed in UCP3 (g.6821C $>\mathrm{T}$ ) and FOXO1 (g.93063G $>$ A and g.93280A $>$ G) genes through sequence analysis. Association analyses suggested that g. $6821 \mathrm{C}>\mathrm{T}$ and g.93280A $>\mathrm{G}$ were associated with carcass quality traits in Qinchuan cattle. These findings imply that both $\mathrm{UCP} 3$ and $\mathrm{FOXO1}$ genes may play an important role in the carcass quality traits, and are potential biomarkers for markerassisted selection and management in feedlot cattle.

\section{Acknowledgments}

The research was supported by the National Natural Science Foundation of Qinghai Province (2018-ZJ-922Q and 2016-ZJ-935Q).

\section{References}

An X., Song Y., Hou J., Wang S., Gao K., Cao B., 2016. Identification of a functional SNP in the 3'-UTR of caprine MTHFR gene that is associated with milk protein levels. Anim. Genet. 47, 499-503, https://doi.org/10.1111/age.12425

Bartz M., Kociucka B., Mankowska M., Switonski M., Szydlowski M., 2014. Transcript level of the porcine ME1 gene is affected by SNP in its 3'UTR, which is also associated with subcutaneous fat thickness. J. Anim. Breed. Genet. 131, 271-278, https://doi. org/10.1111/jbg.12065

Botstein D., White R.L., Skolnick M., Davis R.W., 1980. Construction of a genetic linkage map in man using restriction fragment length polymorphisms. Am. J. Hum. Genet. 32, 314-331

Chakrabarti P., Kandror K.V., 2009. FoxO1 controls insulin-dependent adipose triglyceride lipase (ATGL) expression and lipolysis in adipocytes. J. Biol. Chem. 284, 13296-13300, https://doi. org/10.1074/jbc.C800241200

Changani K.K., Nicholson A., White A., Latcham J.K., Reid D.G., Clapham J.C., 2003. A longitudinal magnetic resonance imaging (MRI) study of differences in abdominal fat distribution between normal mice, and lean overexpressers of mitochondrial uncoupling protein-3 (UCP-3). Diabetes Obes. Metab. 5, 99-105, https://doi.org/10.1046/j.1463-1326.2003.00249.x

Chen W., Xu H., Chen X., Liu Z., Zhang W., Xia D., 2016. Functional and activity analysis of cattle UCP3 promoter with MRFs-related factors. Int. J. Mol. Sci. 17, 682, https://doi.org/10.3390/ ijms 17050682

Chung E.-R., Shin S.-C., Heo J.-P., 2011. Association between SNP marker of uncoupling protein 3 gene and meat yield and marbling score traits in Korean cattle. Korean J. Food Sci. Anim. Resour. 31, 530-536, https://doi.org/10.5851/kosfa.2011.31.4.530

Costford S.R., Chaudhry S.N., Crawford S.A., Salkhordeh M., Harper M.E., 2008. Long-term high-fat feeding induces greater fat storage in mice lacking UCP3. Am. J. Physiol. Endocrinol. Metab. 295, E1018-E1024, https://doi.org/10.1152/ajpendo.00779.2007

Cui H.-X., Liu R.-R., Zhao G.-P., Zheng M.-Q., Chen J.-L., Jie W., 2012. Identification of differentially expressed genes and pathways for intramuscular fat deposition in pectoralis major tissues of fastand slow-growing chickens. BMC Genomics 13, 213, https:// doi.org/10.1186/1471-2164-13-213

Dogan R.I., Getoor L., Wilbur W.J., Mount S.M., 2007. SplicePort-an interactive splice-site analysis tool. Nucleic Acids Res. 35, Suppl. 2, W285-W291, https://doi.org/10.1093/nar/gkm407

Erden Y., Tekin S., Kirbag S., Sandal S., 2015. Mitochondrial uncoupling proteins in the brain: Their structure, function and physiological role. Med. Sci. 4, 2289-2307, https://doi.org/10.5455/medscience.2014.03.8216

Hausman G.J., Basu U., Du M., Fernyhough-Culver M., Dodson M.V., 2014. Intermuscular and intramuscular adipose tissues: Bad vs. good adipose tissues. Adipocyte 3, 242-255, https://doi. org/10.4161/adip.28546

Hou J., An X., Song Y., Gao T., Lei Y., Cao B., 2015. Two mutations in the caprine MTHFR 3'UTR regulated by microRNAs are associated with milk production traits. PLOS ONE 10, e0133015, https://doi.org/10.1371/journal.pone.0133015

Hull J., Campino S., Rowlands K. et al., 2007. Identification of common genetic variation that modulates alternative splicing. PLoS Genet. 3, e99, https://doi.org/10.1371/journal.pgen.0030099

Kim J.J., Li P., Huntley J., Chang J.P., Arden K.C., Olefsky J.M., 2009. FoxO1 haploinsufficiency protects against high-fat diet-induced insulin resistance with enhanced peroxisome proliferator-activated receptor $\mathrm{y}$ activation in adipose tissue. Diabetes 58, 1275-1282, https://doi.org/10.2337/db08-1001 
Lettieri Barbato D., Tatulli G., Aquilano K., Ciriolo M.R., 2013. FoxO1 controls lysosomal acid lipase in adipocytes: implication of lipophagy during nutrient restriction and metformin treatment. Cell Death Dis. 4, e861, https://doi.org/10.1038/cddis.2013.404

Nakae J., Cao Y., Oki M., Orba Y., Sawa H., Kiyonari H., Iskandar K., Suga K., Lombes M., Hayashi Y., 2008. Forkhead transcription factor FoxO1 in adipose tissue regulates energy storage and expenditure. Diabetes 57, 563-576, https://doi. org/10.2337/db07-0698

NRC (National Research Council), 2000. Nutrient Requirements of Beef Cattle. $7^{\text {th }}$ Revised Edition. Update 2000. National Academies Press. Washington, DC (USA), https://doi. org/10.17226/9791

Oliveira B.A.P., Pinhel M.A.S., Nicoletti C.F., Oliveira C.C., Quinhoneiro D.C.G., Noronha N.Y., Marchini J.S., Marchry A.J., Junior W.S., Nonino C.B., 2016. UCP1 and UCP3 expression is associated with lipid and carbohydrate oxidation and body composition. PLOS ONE 11, e0150811, https://doi. org/10.1371/journal.pone.0150811

Pang Y., Wang J., Zhang C., Lei C., Lan X., Yue W., Gu C., Chen D., Chen $H_{\text {., }}$ 2011. The polymorphisms of bovine VEGF gene and their associations with growth traits in Chinese cattle. Mol. Biol. Rep. 38, 755-759, https://doi.org/10.1007/s11033010-0163-6

Ramayo-Caldas Y., Fortes M.R.S., Hudson N.J. et al., 2014. A marker-derived gene network reveals the regulatory role of PPARGC1A, HNF4G, and FOXP3 in intramuscular fat deposition of beef cattle. J. Anim. Sci. 92, 2832-2845, https://doi. org/10.2527/jas.2013-7484

Saltzman E., Roberts S.B., 1995. The role of energy expenditure in energy regulation: findings from a decade of research. Nutr. Rev. 53, 209-220, https://doi.org/10.1111/j.1753-4887.1995. tb01554.x

Seong J., Oh J.D., Cheong I.C., Lee K.W., Lee H.K., Dong S.S., Jeon G.J., Park K.D., Hong S.K., 2011. Association between polymorphisms of Myf5 and POU1F1 genes with growth and carcass traits in Hanwoo (Korean cattle). Genes Genom. 33, 425-430, https://doi.org/10.1007/s13258-011-0006-4
Sparks J.D., Dong H.H., 2009. FoxO1 and hepatic lipid metabolism. Curr. Opin. Lipidology 20, 217-226, https://doi.org/10.1097/ MOL.0b013e32832b3f4c

Sprague J.E., Yang X., Sommers J., Gilman T.L., Mills E.M., 2007. Roles of norepinephrine, free fatty acids, thyroid status, and skeletal muscle uncoupling protein 3 expression in sympathomimetic-induced thermogenesis. J. Pharmacol. Exp. Ther. 320, 274-280, https://doi.org/10.1124/jpet.106.107755

Sun Y., Xue J., Guo W., Li M., Huang Y., Lan X., Lei C., Zhang C., Chen H., 2013. Haplotypes of bovine FoxO1 gene sequence variants and association with growth traits in Qinchuan cattle. J. Genet. 92, Suppl. 2, e8-e14, https://doi.org/10.1007/ s12041-013-0209-3

Toime L.J., Brand M.D., 2010. Uncoupling protein-3 lowers reactive oxygen species production in isolated mitochondria. Free Radical Biol. Med. 49, 606-611, https://doi.org/10.1016/j.freeradbiomed.2010.05.010

Trott J.F., Freking B.A., Hovey R.C., 2014. Variation in the coding and $3^{\prime}$ untranslated regions of the porcine prolactin receptor short form modifies protein expression and function. Anim. Genet. 45, 74-86, https://doi.org/10.1111/age.12100

Wang Y., Yang W., Gui L., Wang H., Zan L., 2016. Association and expression analyses of the Ucp2 and Ucp3 gene polymorphisms with body measurement and meat quality traits in Qinchuan cattle. J. Genet. 95, 939-946, https://doi.org/10.1007/s12041016-0720-4

Yan X., Weijun P., Ning W., Yu W., Wenkai R., Gongshe Y., 2013. Knockdown of both FoxO1 and C/EBP $\beta$ promotes adipogenesis in porcine preadipocytes through feedback regulation. Cell Biol. Int. 37, 905-916, https://doi.org/10.1002/cbin.10115

Zhang R., Li X., 2011. Association between IGF-IR, m-calpain and UCP-3 gene polymorphisms and growth traits in Nanyang cattle. Mol. Biol. Rep. 38, 2179-2184, https://doi.org/10.1007/ s11033-010-0346-1

Zou P., Liu L., Zheng L., Liu L., Stoneman R.E., Cho A., Emery A., Gilbert E.R., Cheng Z., 2014. Targeting FoxO1 with AS1842856 suppresses adipogenesis. Cell Cycle 13, 37593767, https://doi.org/10.4161/15384101.2014.965977 